\title{
Rural women: issues for research, policy and organisation for gender equality
}

\author{
Christine Pelzer White
}

This Bulletin covers a range of themes including research on rural women's economic activities, power relationships between men and women, women's consciousness, solidarity and divisions among women, women's capacity to organise and struggle for a more just society, and the effectiveness of policy measures to promote gender equality in both employment and the family.

Most of the articles here originated as papers discussed at two workshops funded by the International Development Research Centre, Ottawa, and held at the IDS in Spring 1982 under the rubric 'rapid appraisal of the situation of rural women'. One workshop concentrated on a critique of the dominant concepts used in both research work and development policy-making relating to rural societies (most fundamentally, the prevailing definitions of 'work' and 'the household'). The second workshop focused on research techniques. Our aim was to ask a number of leading researchers in the field to summarise the experience of their investigations in a way that would be of use for those undertaking policy oriented research, which often has to be carried out under tight time constraints.

Two obvious questions arise from the title of this Bulletin. Why carry out research focusing particularly on rural women, and what constitutes a feminist methodological approach?

The first question is the easier to answer: research focusing on the female half of the rural population is urgently needed for both analytical and policy related reasons. The relevant established academic fields and disciplines dealing with rural development have largely ignored the fact that the rural population consists of two genders and that the division of labour in rural areas is in many fundamental ways structured along gender lines. To take just two examples, agricultural economics generally treats 'labour' as a concept undifferentiated by gender, while the field of peasant studies abounds with references to the peasant, he' despite the fact that the 'wives and daughters' of male peasants not only carry out tasks crucial to the economic and social survival of maleheaded peasant households but also are often major economic actors in their own right as the primary food producers and as rural traders. The importance of rural women's economic activities in both production and exchange points to the policy relevance of research on rural women since rural development programmes and projects designed without taking into account a major portion of the relevant population can be doomed to failure, or at best partial success, from the start [see Palmer 1979].

Policy makers concerned with agricultural development aim primarily at increasing the productivity of the rural labour force and improving the utilisation of existing natural resources as well as manufactured agricultural inputs. Since a marked sexual division of labour is a major characteristic of the rural labour force in the Third World, to be effective, attempts to increase agricultural productivity need to be informed by an accurate understanding of the different structures of men's and women's work patterns. In short, neither social science research nor development programmes can succeed, even in their own terms of reference, if they omit one half of the population.

It has proven possible, although time consuming and methodologically complex, to quantify women's work and thus begin to correct the erroneous but widespread concept that rural women are 'economically inactive'. Furthermore, the very definition of 'work' has begun to be questioned and the economic as well as social necessity and complexity of women's work in childrearing and household maintenance has begun to be reconsidered, revalued, and even measured. Studies which classify women's housework as 'leisure' still exist, but no longer go unchallenged! This revaluation and recognition of women's work both inside and outside the home has begun to be fed into the planning of rural development projects and programmes. The importance of understanding rural 
women's economic and social role has now been recognised by a number of international development agencies and institutionalised in various ways, among them the inclusion of a description of 'the impact on women' in project evaluation check lists. For example interview protocols and 'fact sheets' to guide the systematic collection of detailed information of the sexual division of labour have been prepared in the ILO and the FAO [Anker 1980; FAO 1983].

This crucial question of how to study the work done by women is dealt with in three articles in this Bulletin. Magdalena Leon analyses the ways in which the definition of work employed in Latin American censuses and surveys has misleadingly omitted and thus rendered invisible most of rural women's work. She emphasises the importance for government planning of measuring accurately the work done by women through improved census and survey categories and collection techniques. As censuses and household surveys provide base line information for both governmental policy planning and social science research, improvement in the collection of this basic data is crucial both for understanding women's economic role and for improved social policy. Ben White provides a comprehensive discussion of various data collection techniques which have been used in time allocation studies for measuring rural work, and evaluates their usefulness in 'rapid rural appraisal'.

Jean Stubbs makes a case for the use of life story interviews as a method of getting at the historical dimension of women's work. In the case of her research in the field of social history she found such interviews the most fruitful way of discovering women's productive roles in a branch of production (cigar making in Cuba) previously thought of by labour historians as male work.

These articles also deal with the strengths and weaknesses of quantitative and qualitative research methods. Ben White makes a convincing case for the usefulness of quantitative research as a tool both for analysis and for convincing policymakers. A major problem is the fact that gender relations is an area particularly subject to cultural norms and preconceptions on the part of researchers, subjects and policymakers alike. For example, both rural men and women, when questioned about work patterns, often state that men do most of the agricultural labour and women only 'help out'. Direct observation has enabled researchers to get beyond this preconception and has demonstrated that in many situations women actually put in as much or more time in the fields as men.

On the other hand, the convention of measuring equally weighted micro units (eg individuals or households) which is necessary for sample survey research tends to separate those units from their social context and the emphasis on measurability and comparability necessarily suppresses or minimises differences. For example, it is a significant difference between male and female work patterns that women often do several tasks simultaneously, while the typical male pattern is single task oriented. Unless such differences are specifically prioritised in the research, female labours still tend to be measured on the grid of male work patterns for the sake of countability and comparability.

Qualitative research techniques, as Jean Stubbs argues, can do a better job of capturing significant differences between the way that men and women experience their work and other aspects of their lives. She found, for example, that "men tell their lives as a series of self-conscious acts using the "I" form, while women, as keepers of the family memory, talk about "we". This male individualism fits in better with the conventions of quantitative social science research. In short, the individualist as well as behaviourist assumptions which underlie most quantitative research methodology constitute obstacles to be overcome in the process of developing a methodology to study rural women. It is highly misleading to analyse women as individual actors on the model of the self-activated 'economic man' because women generally are far more deeply embedded in, and constrained by, their kin relationships connected with biological reproduction than is the case for men [see Thorne and Yalom 1982]. Furthermore, while a behaviourist approach to the study of work can demonstrably make major contributions to our understanding of women's lives, there are a number of crucial questions which are neither asked nor answered within this methodology: what is the consciousness behind an act; why do women accept heavier work burdens; where does the energy and direction for social change come from? In short, there is a need for both quantitative and qualitative research techniques in the development of the methodology of this field of study.

There is still much to be done, and many academic and bureaucratic battles to be fought, before women's economic activities are adequately reflected in censuses and household surveys and routinely recognised in rural development programmes and projects. However, these tasks can be described as being in the relatively uncontroversial area of 'getting the facts straight' concerning economic productivity. What distinguishes the more controversial and specifically feminist viewpoint in research on rural women is to be found in the more normative area of social relations and values. The feminist view which permeates the work of the IDS Subordination of Women cluster is that not only do existing socioeconomic systems structure the work, leisure and life- 
chances of men and women differently, but that these differences add up to systematic inequality between the sexes, and more than that, pervasive subordination of women by men. Research on patterns of gender inequality and women's subordination is needed in order to develop new concepts and policies for forms of development which can improve the social, economic and political status of women on a par with men. Since the high priority placed by feminists on transforming gender inequality and subordination has not yet found general acceptance in either academic or policy making circles, this research is more controversial than simply finding out who does what work in the rural sexual division of labour in order to increase economic productivity.

This research is not only more controversial, it is also more difficult and complex methodologically. 'Inequality' and 'subordination' are abstract concepts which are difficult to define and measure. While gender stereotyped steps in agricultural production, such as ploughing and transplanting in many rice growing rural economies, have specific cultural meanings, they can be analysed as acts carried out by individuals over a given time, and therefore measured on a universalised grid of individual-act-duration in quantitative social science research. Acts of subordination are not as easily captured by quantitative techniques: the concept 'subordination', unlike 'work', refers to a relationship, not an individual. Relational acts are not only difficult to measure but also cannot be accurately interpreted without a deep understanding of the cultural context. Furthermore, subordination is a power relationship, and power is more elusive to measure than time and motion.
Ben White discusses the difficulties he encountered in trying to develop a method to measure and quantify conjugal power relations, in this case by looking at the relative dominance of husband and wife in decision making. He concludes that apparent 'dominance' in particular areas of decision making (eg, decisions on buying food or buying fertiliser) are not necessarily reliable indices of power relations. For example, a husband might leave a decision to his wife because this saves him time and bother, and their relationship is such that he can be sure that she would not do anything he would disagree with. In other words, identifying an apparent decision maker does not necessarily tell us much about the question of gender inequality and subordination. On the other hand, this research does break-down the usual conception of exclusive male responsibility for production and female responsibility for domestic matters.

\section{Women's Consciousness}

Women's consciousness of unequal gender relationships is the primary determinant of their capacity for organisation for social change. In the lead article in this Bulletin Ann Whitehead examines the factors underlying solidarity as well as divisions among women. The existence of or potential for women's consciousness of a community of interest can be important for researchers, policy-makers and grass roots activists alike. Women's interests are shown to be complex, and the category 'women' not a homogeneous group. Gender, class and kinship all deeply influence women's lives, creating complex patterns of mutual support as well as oppression between women and women and between men and women.

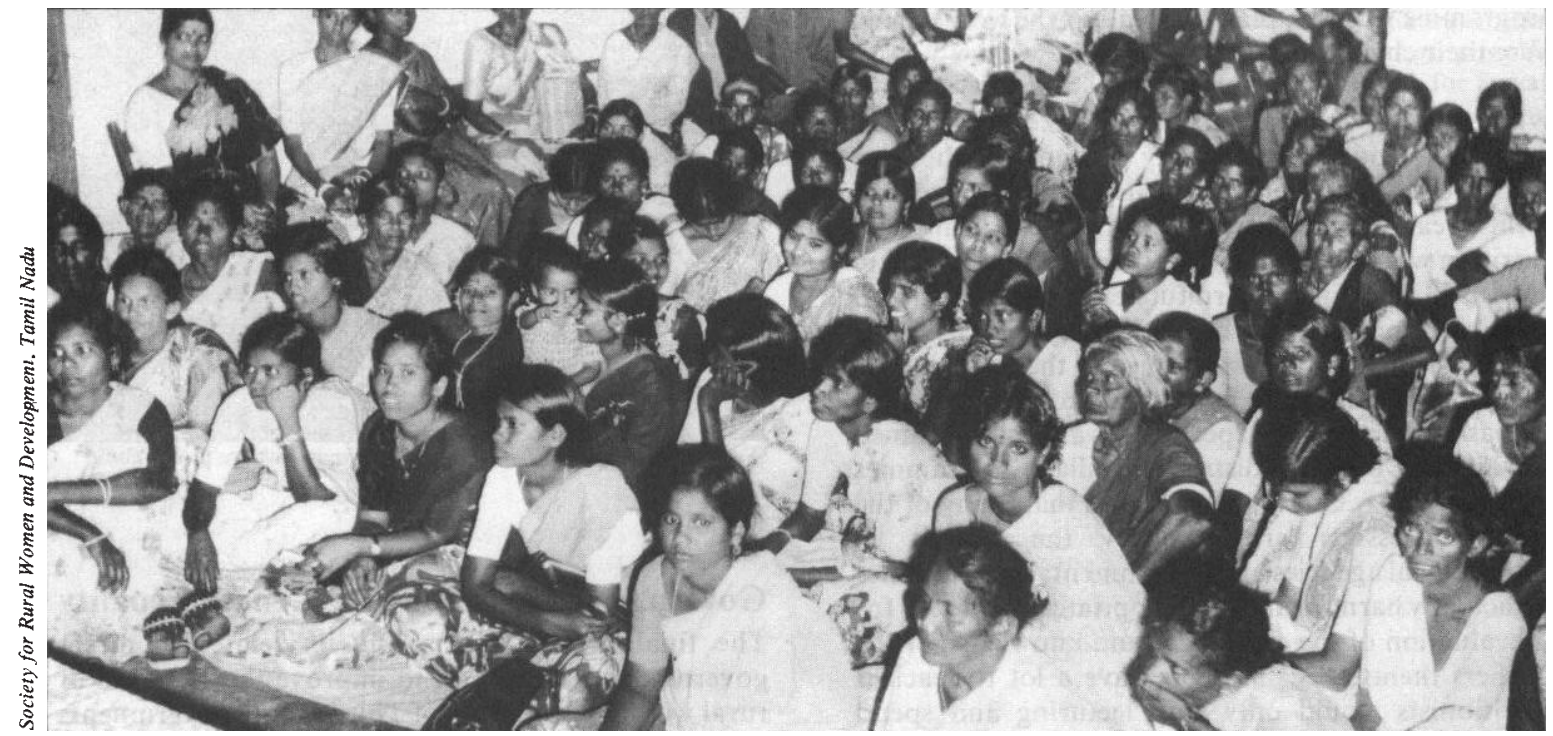

Organising rural women 
The implications of Ann Whitehead's analytical discussion of the material basis of gender, class and family consciousness emerge clearly in Burnad Fatima's account of her experience in building a rural women's liberation movement among landless labourers in South India. While men and women of the same class work together on a range of problems, women have found it necessary to form a separate organisation in order to deal with a number of gender issues including women's health and wages as well as unequal conjugal relationships. Like Ann Whitehead, Fatima finds the differences between women which stem from their position in the family/life cycle to be important, but these are discussed primarily as facilitators or constraints on women's organisational activities rather than as the basis of conflicts of interest. In her organisation, village health workers are recruited and trained partly on the basis of their family status: priority is given to training widows both in order to give this stigmatised category of women a new and valued social role, and because they have extra time to devote to social service work since widowhood reduces their domestic responsibilities. By the same token, young unmarried women are generally not trained as health workers because of the likelihood that marriage and young children would soon force them to discontinue their work.

\section{Respecting Women's Knowledge}

Burnad Fatima argues strongly for mobilising the potential and capacities of women (as well as men) as the most important route for the development of a better society. Gill Gordon puts forward a similar argument from the point of view of someone who worked for many years in a government nutrition programme which implicitly devalued the women who were their chief 'target group'.

While women's role as mothers, unlike their role as economic producers, is widely recognised, they are hardly respected by 'professionals' as 'knowledgeable' in this area. Indeed, an assumption of much health and nutrition work is that most mothers are inadequate in their task, engaging in harmful health and nutritional practices which can best be rectified by their listening to and learning the wisdom of the experts (ie behaviour modification by trained professionals). On the basis of nine years' experience as a Western trained nutritionist working in district and village programmes in West Africa, Gill Gordon argues that many of the nutrition lessons promoted by the experts in international agencies and governmental programmes are actually harmful and ina ppropriate. She argues for a revaluation of the experience and knowledge of the mothers themselves: 'mothers have a lot to teach if nutritionists would only stop lecturing and spend more time listening'. If nutritionists would learn more from the mothers' specialised knowledge of local food availability, economic and time constraints in food preparation and child feeding, etc, th is could lead to more effective strategies for improving child nutrition. Nutritionists will only be able to change the consciousness and behaviour of their 'target group', mothers, if they change their own consciousness and behaviour by respecting women's knowledge of their own situation.

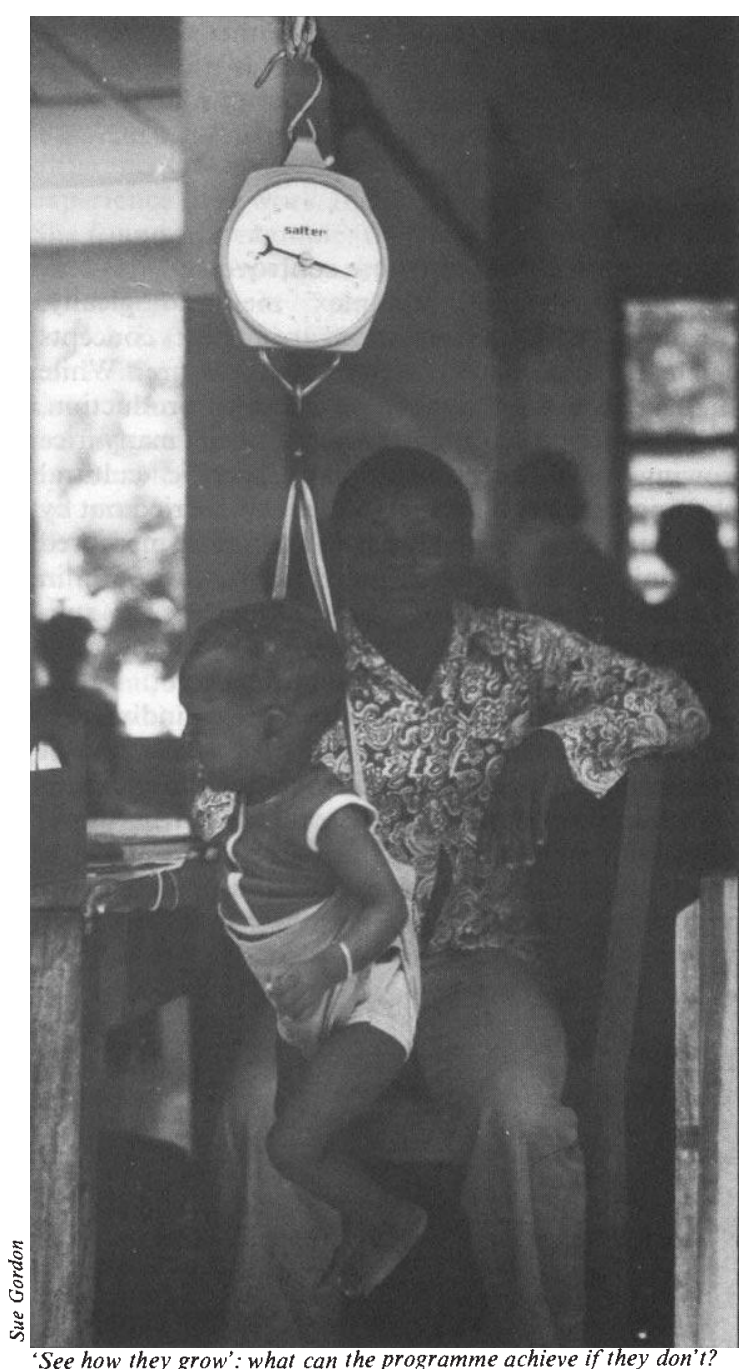

\section{Government Legislation for Gender Equality}

The final theme of this Bulletin relates to direct government intervention to improve the situation of rural women. A number of Third World governments have an explicit official commitment to promote 
women's equality and involve women fully in national development programmes. Both the progress and continued problems in such countries are of particular interest for feminists as illustrations of the potential and limits of government action for women's equality and liberation. Such cases can provide valuable experience to improve the design of appropriate policy measures for women's liberation in the future. This Bulletin includes two articles on countries with a strong official commitment to achieving equality between men and women: China and Vietnam. One striking finding by Elisabeth Croll in her work on China is that official norms concerning gender equality can, ironically, impede research on the implementation of policies designed to enhance women's equality, since both interviews and documentary sources tend to present what 'ought to be' as opposed to what 'is'. In such a context questions too closely connected to norms and policy implementation tend to elicit misleading information; concrete observation and factual questions at the household level are most useful as indications of the real extent of social change.

A colloquium on Women, employment and the family held in Hanoi in March 1983, organised jointly by the IDS Subordination of Women cluster and the Vietnamese Social Sciences Research Commission, focused on the question of appropriate legislation and policies to promote women's equality in both place of work and the family. In a context where there are no legal impediments to gender equality, social attitudes and the weight of women's double burden of work, along with the economic constraints in a poor country, constitute the main impediments to achieving full equality. For example, working women's household and childcare responsibilities make it more difficult for them to take advantage of training facilities for career advancement which are theoretically open to them on a par with men. There are, furthermore, rather narrow limits to the extent that legislation can transform society: as in most Third World countries, the impact of state employment policy and legislation is primarily limited to the urban population of workers and civil servants; the rural population, whether working in family agriculture or organised into producer cooperatives, is not directly dependent on the state for the provision of food and wages and is more influenced by traditional socio-economic arrangements and custom. In this context research on rural women could play a significant role in identifying the areas where state policy could play a transformative role.

\section{Conclusion}

This issue brings together articles by people involved in research, grass roots organising and government development programmes in an attempt to show the interrelatedness of these three areas of endeavour for those committed to progress toward gender equality. Perhaps the most basic common theme is that good and effective work, whether in research, grass roots organising or government policy making and implementation, must be based on respect for, and involvement of, rural women themselves.

\section{References}

Anker, Richard, 1980, Research on Women's Roles and Demographic Change: survey questionnaires for households, women, men and communities with background explanations, Population and Labour Policies Programme, ILO World Employment Programme, Geneva

FAO, 1983, 'Country fact sheets to identify women's role in agriculture and food production', Rome, mimeo

Palmer, Ingrid, 1979, The Nemow Case: case studies of the impact of development projects on women, Working Paper no 7, Population Council, New York

-and Ulrike von Buchwald, 1980, Monitoring Changes in the Conditions of Women: a critical review of possible approaches, United Nations Research Institute for Social Development, Geneva

Thorne, Barrie and Marilyn Yalom (eds), 1982, Rethinking the Family: some feminist questions, Longman, New York 